Military Technical College Kobry El-Kobbah, Cairo, Egypt

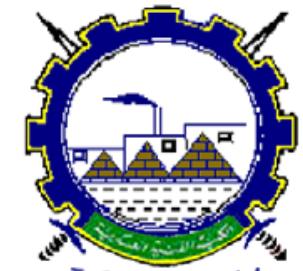

I.C.E.E.2014 $7^{\text {th }}$ International Conference

on

Chemical \& Environmental

Engineering

27 - 29 May, 2014.

\title{
CEEA-2
}

\section{Effect of Hydrogen Peroxide Addition on the Photochemical and Sonochemical Destruction of Pyridine in Wastewater}

\author{
M. A. Elsayed ${ }^{1}$
}

\begin{abstract}
Pyridine and its derivatives have potential impact to various environment segments due to its persistent nature and are normally found in wastewater. The photochemical and sonochemical degradation of aqueous solutions of pyridine have been investigated by means of ultraviolet (UV), ultrasound (US), $\mathrm{UV} / \mathrm{H}_{2} \mathrm{O}_{2}$ and $\mathrm{US} / \mathrm{H}_{2} \mathrm{O}_{2}$ irradiation processes. The pure photochemical process demonstrated to be efficient for degradation of low initial concentrations of pyridine (10ppm). While sonochemical degradation proceeded very slowly, leading to less than $53 \%$ of pyridine removal after 200 min. The degradation efficiency was increased with increase $\mathrm{H}_{2} \mathrm{O}_{2}$ concentration; however, the marginal benefit became decreasing with further increasing of $\mathrm{H}_{2} \mathrm{O}_{2}$ due to the scavenging effect of excess $\mathrm{H}_{2} \mathrm{O}_{2}$. The kinetics of photochemical and sonochemical degradation of pyridine were found to follow a first-order rate law. A possible degradation pathway for pyridine was also proposed.
\end{abstract}

Key words:

pyridine, sonochemical degradation, photochemical degradation, wastewater treatment

1 Egyptian Armed Forces, Cairo, Egypt

Corresponding author. Tel.:+201141750544; fax: +222621918

E-mail address:aboelfotoh@gmail.com 


\section{Introduction:}

Ultraviolet and ultrasound irradiation are highly efficient and novel methods for the rapid oxidation/degradation of many organic and inorganic substances. In the recent years, these advanced oxidation processes (AOPs) have emerged as potentially powerful methods for transforming organic pollutants into non-toxic substances [1]. The most widely adopted AOPs include photodegradation, Fenton, photo-Fenton, ultrasonication and ozonation $\left(\mathrm{O}_{3}\right)$. AOPs are based on physicochemical processes that produce in situ powerful free radical species, principally hydroxyl radicals (HO•), by using chemical and/or other forms of energy, and have a high efficiency for organic matter oxidation;. It is highly powerful oxidizing agent having an oxidation potential of $2.33 \mathrm{~V}$, which can undergo rapid and non-selective reaction with most organic and many inorganic pollutant. Hydroxyl radicals exhibit faster rates of oxidation reactions comparing to conventional oxidants such as $\mathrm{H}_{2} \mathrm{O}_{2}$ or $\mathrm{KMnO}_{4}$ [2]. Once generated, the hydroxyl radicals can attack organic chemicals by radical addition [3].

Unlike conventional physicochemical prcesses, AOPs provide faster reaction rate; at the same time, AOPs are effective in the removal of various organics present in water and wastewater [4,5].

The increasing contamination of wastewater streams by organic species refractory to conventional methods has promoted the development of newer technologies able to degrade these contaminants. Advanced oxidation processes (AOPs) are efficient novel methods useful to accelerate the non-selective oxidation and thus the destruction of a wide range of organic substances resistant to conventional technologies [6 - 8]. Since pyridine is a common refractory pollutant in wastewater effluents, the conventional volatile organic compound (VOC) control technologies, including condensation, adsorption [9], extraction, membrane separation and so on, have been commonly utilized to control its escaping. However, these technologies require high operating costs or secondary disposal treatments [10]. Biological means of treatment transforms the pollutants present in the waste to certain intermediate compounds, which are further mineralized/utilized in the metabolic pathway. Even though the biological methods are highly practical and advantageous, the toxic and hazardous compounds encountered in the waste inhibit the process [11,12].

A lack in literature reports regarding safe removal of pyridine compound and their transformation products and comparison of different degradation techniques was noticed. On the basis of the previous considerations, this study focused on the photochemical and sonochemical degradation of pyridine in aqueous media. A variety of different operating conditions were examined. The effects of different initial concentrations and $\mathrm{H}_{2} \mathrm{O}_{2}$ on kinetic rate constants were also examined in order to gain insight into the kinetics of the degradation of pyridine.

\section{Materials and methods}

\subsection{Materials}

Pyridine standard solution was supplied by Fluka with purity better than $98.0 \%$. It was used to prepare a synthetic wastewater. Aqueous solutions were made using deionized water. All other reagents were reagent grad obtained from Fluka and used as received.

\section{2 ultrasonic setup reactor}

The degradation experiments were carried out in ultrasonic cleaner bath (Honda electronics PS-60, Capacity $15 \mathrm{~L}$ ). The bath operates at $360 \mathrm{~W}$ and $40 \mathrm{kHz}$. Erlenmeyer flask was used as reaction vessel. The volume of the solution was $100 \mathrm{ml}$. The bath temperatures were maintained by proper recirculation of water. Solution temperature was also monitored regularly. The efficiency of a reaction vessel placed in an ultrasonic bath depends strongly on the distance of the bottom of the reaction vessel to the bottom of water bath. The distance was carefully measured through preliminary experiments, so that ultrasonic intensity reached 
maximum at the bottom of the flask. For ultrasonic frequency $40 \mathrm{kHz}$ this distance value was $1 \mathrm{~cm}$. The reactor was sealed with silicone stopper wrapped with an aluminium foil to ensure the minimum loss due to evaporation of the volatile compounds. The syringe needle was pierced through the septum of the stopper for sampling. All sonochemical experiments were conducted twice in parallel. The averages of the parallel experimental data were calculated and taken into account in analyses of sonochemical kinetics. The error of all parallel experiments was under $5 \%$.

\subsection{Photochemical setup reactor}

The experiments were carried out in a $250 \mathrm{ml}$ glass immersion photochemical reactor, charged with $100 \mathrm{ml}$ of aqueous solution, where the solution is illuminated by means of a low-pressure, $10 \mathrm{~W}$, mercury lamp with $90 \%$ emission at $254 \mathrm{~nm}$, located axially and held in a quartz immersion tube. The source was turned on and the time count initiated. Samples (ca. $5 \mathrm{ml}$ ) were withdrawn at regular times for UV-Vis analysis.

\subsection{Quantitative analysis experiments}

Samples periodically drawn from the vessel were quantitatively analysed by measuring its absorbance using Shimadzu UV-visible spectrophotometer. Initially tests were carried out by UV scans from a wavelength of 200 to $500 \mathrm{~nm}$ to determine the absorption maxima of the pyridine molecule.

\section{Results and discussion}

\subsection{Optimization of the operating conditions}

\subsubsection{Effect of initial pyridine concentration}

Since the industrial wastewater contains pollutants in varying concentration, the effect of initial concentrations on the reaction rate was tested for pyridine. The effect of initial concentration on the degradation of pyridine was investigated at initial concentration of 10 and $100 \mathrm{mg} / \mathrm{L}$ for both photochemical and sonochemical experiments.

As shown in Figure 1 with increase in irradiation time, the concentration of pyridine in the solution is decreases and thus the removal increases. It follows from the data obtained that degradation of pyridine depends upon irradiation time. For the sonochemical irradiation experiments, the removal rates of pyridine decreased from $43 \%$ to $13 \%$ with increasing the initial concentration from 10 to $100 \mathrm{mg} / \mathrm{L}$, respectively as shown in Figure 2. This suggests that increasing the initial concentration of the solution would decrease the removal rates of pyridine. This is because the increment of initial concentration of the volatiles results in the weakening effect of cavitation reactions [13]. However, the total amount of pyridine degraded after $60 \mathrm{~min}$ at $100 \mathrm{mg} / \mathrm{L}$ was as much as three times larger than that degraded at 10 $\mathrm{mg} / \mathrm{L}$. On the other hand, the photochemical experiments show a better removal of pyridine. The removal rates of pyridine decreased from $90 \%$ to $60 \%$ with increasing the initial concentration from 10 to $100 \mathrm{mg} / \mathrm{L}$, respectively. These indicate that, ultraviolet irradiation is far more effective than ultrasound irradiation in the degradation of pyridine in aqueous solution. The results show that the removal efficiency using photochemical process is approximately $90 \%$ at pyridine initial concentration $10 \mathrm{ppm}$, so it can be said that achieved a complete mineralization of the pyridine. While, the process of ultrasound achieves an efficiency of $43 \%$ for the same initial concentration and irradiation time $60 \mathrm{~min}$. 


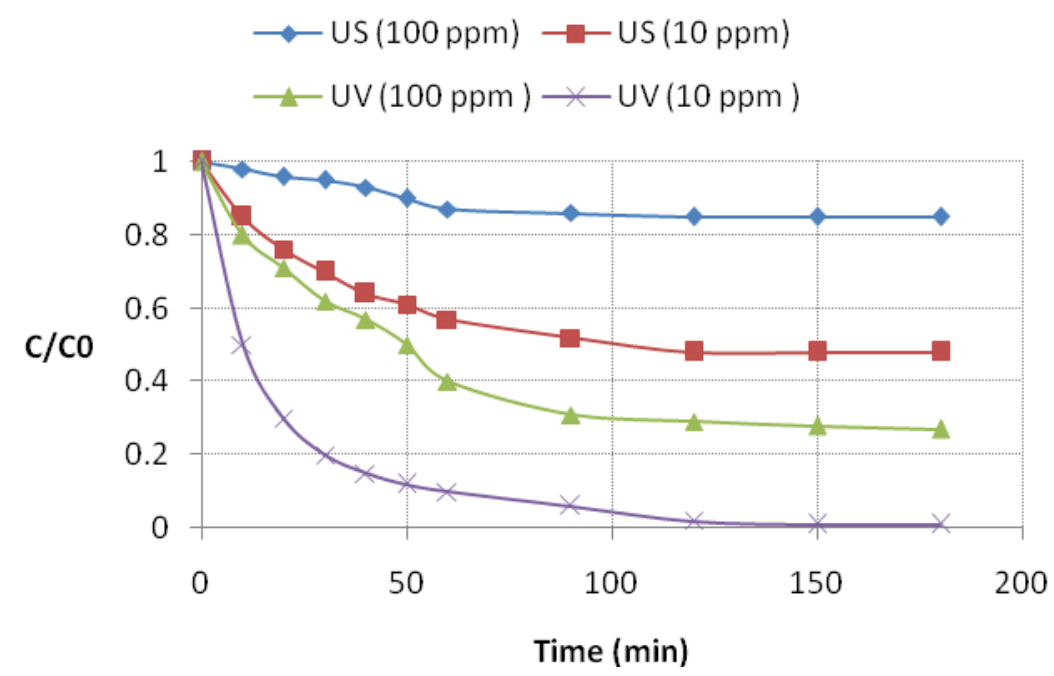

Fig.1 Effect of initial concentration on the degradation of pyridine for both ultrasound (US) and ultraviolet (UV) experiments at $\left(25^{\circ} \mathrm{C}\right)$.

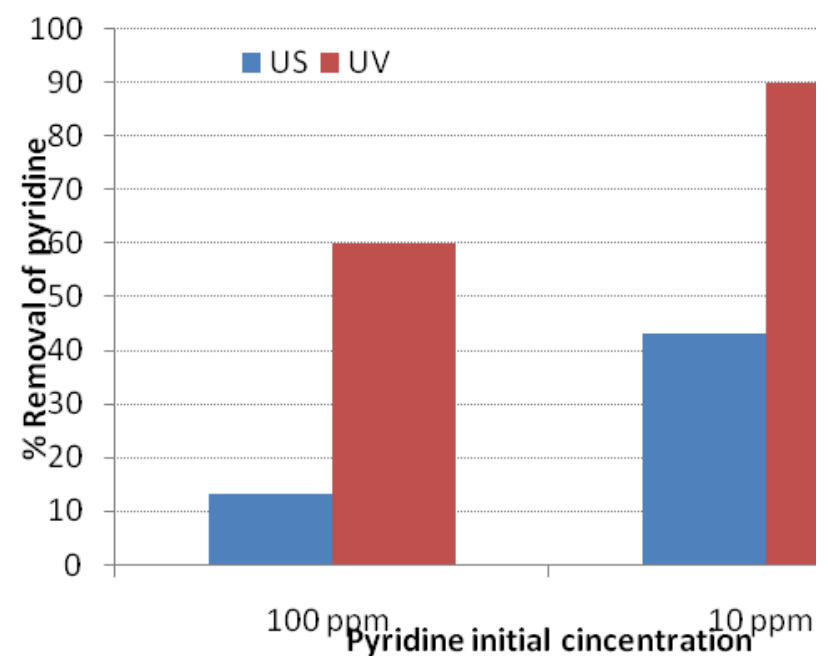

Fig. $2 \%$ Removal of pyridine after 60 min irradiation time for both ultrasound (US) and ultraviolet (UV) experiments at $\left(25^{\circ} \mathrm{C}\right)$.

The degradation curves of pyridine by UV and US radiation are well fitted by a monoexponential curve, suggesting that a first-order homogeneous reaction model can be taken in consideration for describing the kinetic behavior. Considering that the UV and US radiation are the sole responsible for pyridine removal from the solution, and considering that the limiting step is the scission of the starting material, the kinetic equation that describes the process is

$$
-\frac{d C}{d t}=k C
$$

with $k$ is the first-order rate constant and $C$ is the concentration of pyridine at any moment where $t>0$. Integration of Eq. (4), with the usual condition of $C=C_{0}$ at $t=0$, will lead to a linear plot of $\ln \left(C_{0} / C\right)$ versus $t$ with a slope of $k$, the first-order rate constant Figure 3. The photochemical and sonochemical experiments under conditions of constant irradiating flux for different initial concentrations of pyridine show a variation in the $k$ values (Table 1 ). The 
apparent first order rate constants decreased with an increasing initial concentration of the pyridine, indicating non-elementary nature of the sonochemical and photochemical reactions. This dependence of reaction rate constants on initial concentration agreed well with existing literature [14-17].

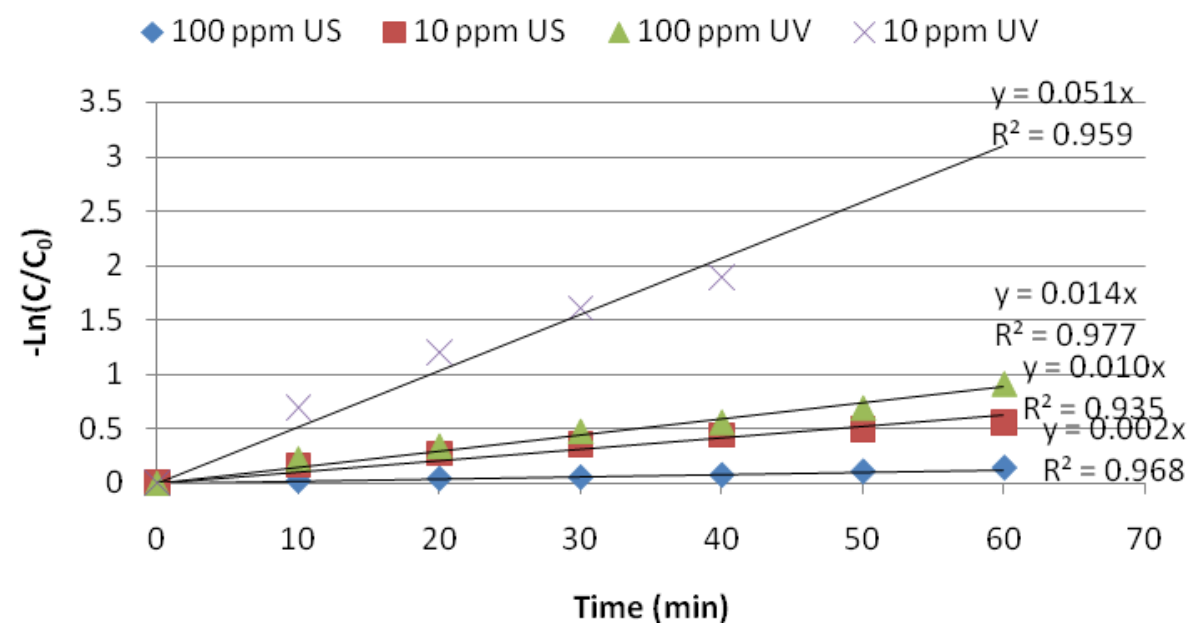

Fig. 3 The First order Kinetics of pyridine degradation at initial concentration of 10 and 100 $\mathrm{mg} / \mathrm{L}$ for both photochemical and sonochemical experiments at $\left(25^{0} \mathrm{C}\right)$.

Table 1. The apparent first order rate constants and half-life time for the pyridine degradation processes

\begin{tabular}{cccc}
\hline $\begin{array}{c}\text { Type of process/ Initial } \\
\text { pyridine concentration }(\mathrm{ppm})\end{array}$ & $\begin{array}{c}\text { Rate constant } \\
k\left(\mathrm{~min}^{-1}\right)\end{array}$ & $\mathrm{T}_{1 / 2}(\mathrm{~min})$ & $\mathrm{R}^{2}$ \\
\hline US $(10 \mathrm{ppm})$ & 0.01 & 90 & 0.93 \\
US (100 ppm) & 0.002 & $>200$ & 0.97 \\
UV (10 ppm) & 0.051 & 10 & 0.95 \\
UV (100 ppm) & 0.014 & 50 & 0.98 \\
\hline
\end{tabular}

For sonochemical experiment, 10 -fold increase in the initial concentration of the pyridine leads to a 5-fold decrease on the rate constant of the process. While, for the photochemical experiment, 10 -fold increase in the initial concentration of the pyridine leads to a 4-fold decrease on the rate constant. The observed decrease on $k$ as the initial concentration of the pyridine increases can be explained in terms of the less availability of oxidizing species, such as $\mathrm{OH}$ radicals, through the direct photolysis or sonolysis of $\mathrm{H}_{2} \mathrm{O}$ as the concentration of the solution gets more intense. Comparison of photo-degradation and sono-degradation processes efficiencies showed that photo-degradation of pyridine was more efficient than sonodegradation. It can also be observed from results that UV had its potential to degrade pyridine. More than $90 \%$ degradation was achieved after about $60 \mathrm{~min}$ at $10 \mathrm{ppm}$ of pyridine. The poor effects of US alone on the degradation efficiency may be attributed to the fact that low ultrasound frequencies hinder the development of hydroxyl radicals [18]. Hence, for pyridine, a volatile and highly soluble compound, reactions inside or in the vicinity of the bubble, where fast thermal decomposition and increased concentrations of radicals exist, are unlikely to occur to an appreciable extent and, therefore, its degradation will be driven by hydroxyl radical-mediated secondary activity in the liquid bulk. Thus US irradiation process generally demands a high contact time for significant degradation efficiency [19]. On the 
other hand, UV irradiation had high potential to produce the highly reactive hydroxyl radical. This would explain discrepancies in reactivity of pyridine between sonochemical and photolytic reactions since the latter involve the participation of a more diverse range of reactive species (i.e., radicals and electrons) than the former [21]. Generally, the photolysis degradation can be defined as a cyclic photo process in which pyridine photodegrades, but spontaneous regeneration of catalyst occurs to allow the sequence to continue indefinitely until all the substrate is destroyed [ 22].

\subsubsection{Effect of $\mathrm{UV} / \mathrm{H}_{2} \mathrm{O}_{2}$ and $\mathrm{US} / \mathrm{H}_{2} \mathrm{O}_{2}$ irradiation processes.}

Hydroxyl radicals generated in water by ultrasonication and photolysis can produce hydrogen peroxide in the system according to equations (2)-(14). In these reactions “)))" denotes the UV or US irradiation. Whether additional hydrogen peroxide has a synergistic effect on the overall degradation of pollutants [23, 24], for this purpose some experiments were conducted at various concentrations of added $\mathrm{H}_{2} \mathrm{O}_{2}$.

$$
\begin{aligned}
& \left.\left.\left.\mathrm{H}_{2} \mathrm{O}+\right)\right)\right) \rightarrow \cdot \bullet \mathrm{OH}+\cdot \mathbf{H} \\
& \mathrm{O}_{2}(\text { dissolved) }+ \text { )) }) \rightarrow 2 \cdot \mathrm{O} \\
& \cdot \mathrm{OH}+\cdot \mathrm{O} \rightarrow \cdot \mathrm{OOH} \\
& \cdot \mathrm{O}+\mathrm{H}_{2} \mathrm{O} \rightarrow 2 \cdot \mathrm{OH} \\
& \cdot \mathrm{H}+\mathrm{O}_{2} \rightarrow \cdot \mathrm{OOH} \\
& \bullet \mathrm{OH}+\cdot \mathrm{H} \rightarrow \mathrm{H}_{2} \mathrm{O} \\
& 2 \cdot \mathrm{OH} \rightarrow \mathrm{H}_{2} \mathrm{O}+\bullet \mathrm{O} \\
& \cdot \mathrm{OOH}+\cdot \mathrm{OH} \rightarrow \mathrm{O}_{2}+\mathrm{H}_{2} \mathrm{O} \\
& 2 \cdot \mathrm{OH} \rightarrow \mathrm{H}_{2} \mathrm{O}_{2} \\
& 2 \cdot \mathrm{OOH} \rightarrow \mathrm{H}_{2} \mathrm{O}_{2}+\mathrm{O}_{2} \\
& \cdot \mathrm{H}+\mathrm{H}_{2} \mathrm{O}_{2} \rightarrow \cdot \mathrm{OH}+\mathrm{H}_{2} \mathrm{O} \\
& \cdot \mathrm{OH}+\mathrm{H}_{2} \mathrm{O}_{2} \rightarrow \cdot \mathrm{OOH}+\mathrm{H}_{2} \mathrm{O} \\
& 2 \cdot \mathrm{H} \rightarrow \mathrm{H}_{2}
\end{aligned}
$$

In this part of study, sonication and photoloysis experiments were repeated with pyridine solutions including $\mathrm{H}_{2} \mathrm{O}_{2}$ to study the effect of $\mathrm{H}_{2} \mathrm{O}_{2}$ addition on degradation of pyridine. $\mathrm{H}_{2} \mathrm{O}_{2}$ was added to $100 \mathrm{ml}$ pyridine solution with initial concentration of $100 \mathrm{ppm}$ in such amount that its concentration was $100 \mathrm{ppm}, 300 \mathrm{ppm}$ or $500 \mathrm{ppm}$ in solution. Figure 4 displays the effect of $\mathrm{H}_{2} \mathrm{O}_{2}$ amount added on sonochemical degradation of pyridine, while the embedded Figure shows the reaction kinetics for the degradation, in which all reactions kinetics followed first-order rate laws $\left(\mathrm{R}^{2}>93\right)$. As seen from Figure 4 , in the concentration range studied the amount of $\mathrm{H}_{2} \mathrm{O}_{2}$ added has positive contribution on the degradation of pyridine when compared with the absence of $\mathrm{H}_{2} \mathrm{O}_{2}$. Increasing the amount of $\mathrm{H}_{2} \mathrm{O}_{2}$ increases the degradation of pyridine at constant temperature $25^{\circ} \mathrm{C}$. 


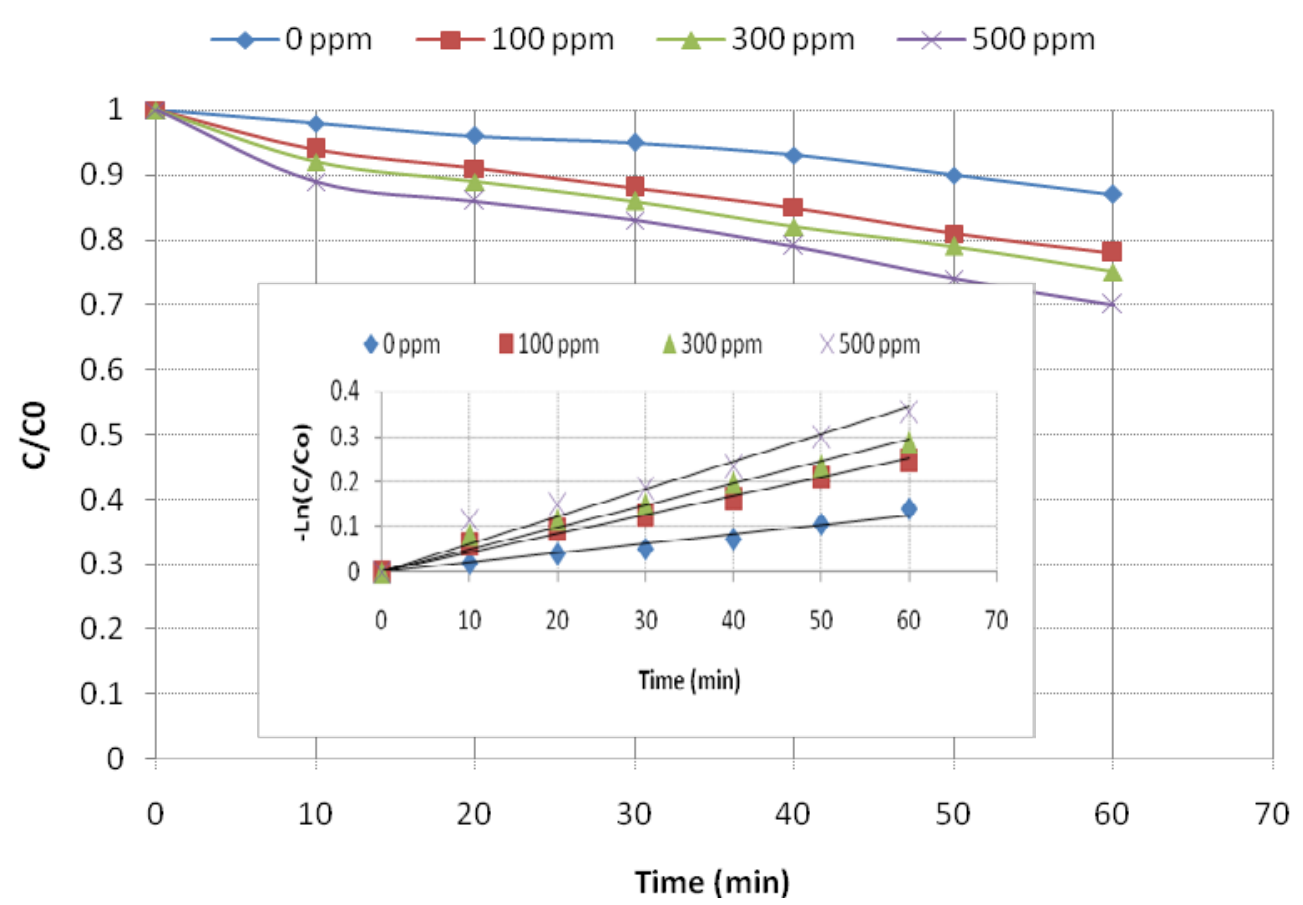

Fig. 4 Effect of $\mathrm{H}_{2} \mathrm{O}_{2}$ concentration on the sonochemical degradation of pyridine at initial concentration of pyridine $\mathrm{C}_{0}=100 \mathrm{ppm}$. Embedded curve shows the first order kinetics of pyridine degradation at $25{ }^{\circ} \mathrm{C}$.

According to the theory of hot spot, the temperature and pressure of localized hot spots formed can excessively reach $5000 \mathrm{~K}$ and 1000 atm respectively in the ultrasonic cavitation. Under these conditions, hydrogen peroxide readily decomposes into hydroxyl radicals, according to the following equations, causing high degradation rate [ 25].

$$
\begin{aligned}
& \mathrm{H}_{2} \mathrm{O}_{2}+\text { us } \rightarrow 2 \cdot \mathrm{OH} \\
& \mathrm{H}+\mathrm{H}_{2} \mathrm{O}_{2} \rightarrow \cdot \mathrm{OH}+\mathrm{H}_{2} \mathrm{O}
\end{aligned}
$$

The amount of $\mathrm{H}_{2} \mathrm{O}_{2}$ that can be produced by ultrasound itself is too small to dissociate into large amount of $\bullet \mathrm{OH}$. Thus, additional amount of $\mathrm{H}_{2} \mathrm{O}_{2}$ is generally needed to significantly accelerate the degradation process. $\mathrm{H}_{2} \mathrm{O}_{2}$ will increase the formation of $\bullet \mathrm{OH}$ in two ways. It could either through the self-decomposition as a result of ultrasound irradiation or as the reduction of $\mathrm{H}_{2} \mathrm{O}_{2}$ at the conduction band as shown in reactions (15) and (16), respectively [26].

Figure 5 shows the effect of different $\mathrm{H}_{2} \mathrm{O}_{2}$ concentrations on degradation of pyridine with respect to irradiation time. It can be seen that the photodegradation increases with the increase of $\mathrm{H}_{2} \mathrm{O}_{2}$ concentration, up to the optimum value and then decreases when the $\mathrm{H}_{2} \mathrm{O}_{2}$ concentration is increased. This trend can be explained by the fact that $\mathrm{H}_{2} \mathrm{O}_{2}$ itself acts as an effective hydroxyl radical scavenger at concentrations that are specific for the pollutant in question.

Figure 6 displays the effect of $\mathrm{H}_{2} \mathrm{O}_{2}$ amount added on the rate of photochemical degradation of pyridine in aqueous solution. As it can be seen from the curve, addition of $100 \mathrm{ppm}$ and $300 \mathrm{ppm} \mathrm{H}_{2} \mathrm{O}_{2}$ can enhance the degradation when compared with the absence of $\mathrm{H}_{2} \mathrm{O}_{2}$. However, $500 \mathrm{ppm} \mathrm{H}_{2} \mathrm{O}_{2}$ has negative contribution on the decomposition of pyridine. So there may be an optimum amount of $\mathrm{H}_{2} \mathrm{O}_{2}$ to increase the degradation rate. 


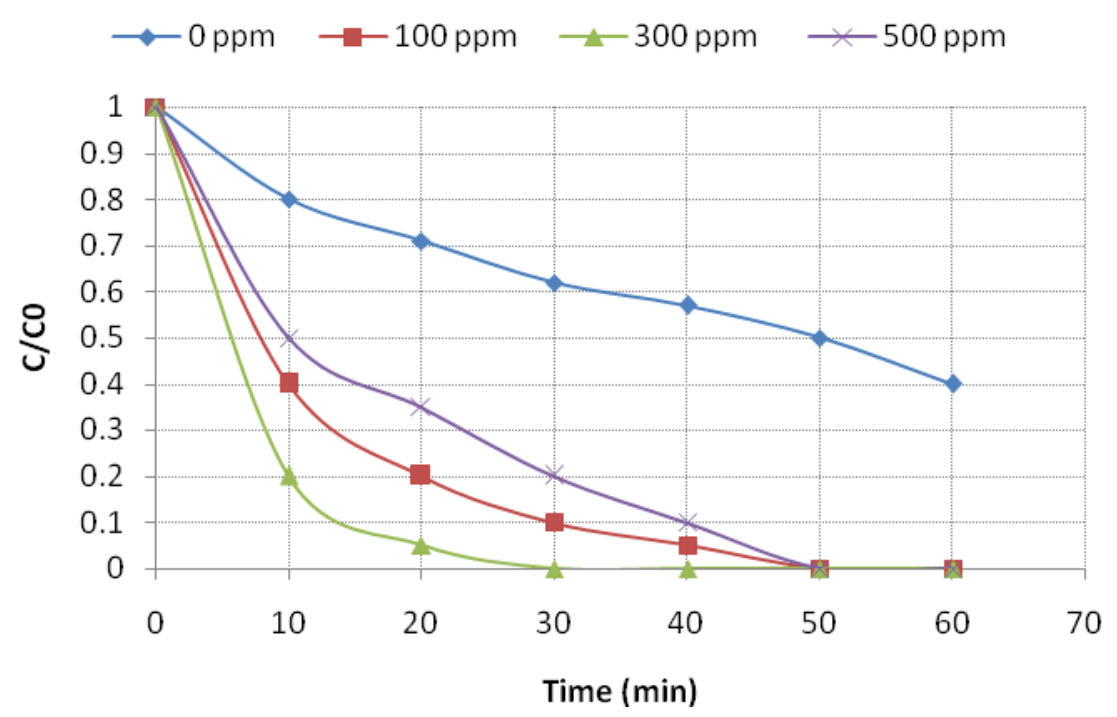

Fig. 5 Effect of $\mathrm{H}_{2} \mathrm{O}_{2}$ on the photochemical degradation of pyridine at initial concentration of pyridine $\mathrm{C}_{0}=100 \mathrm{ppm}$ at $25^{\circ} \mathrm{C}$.

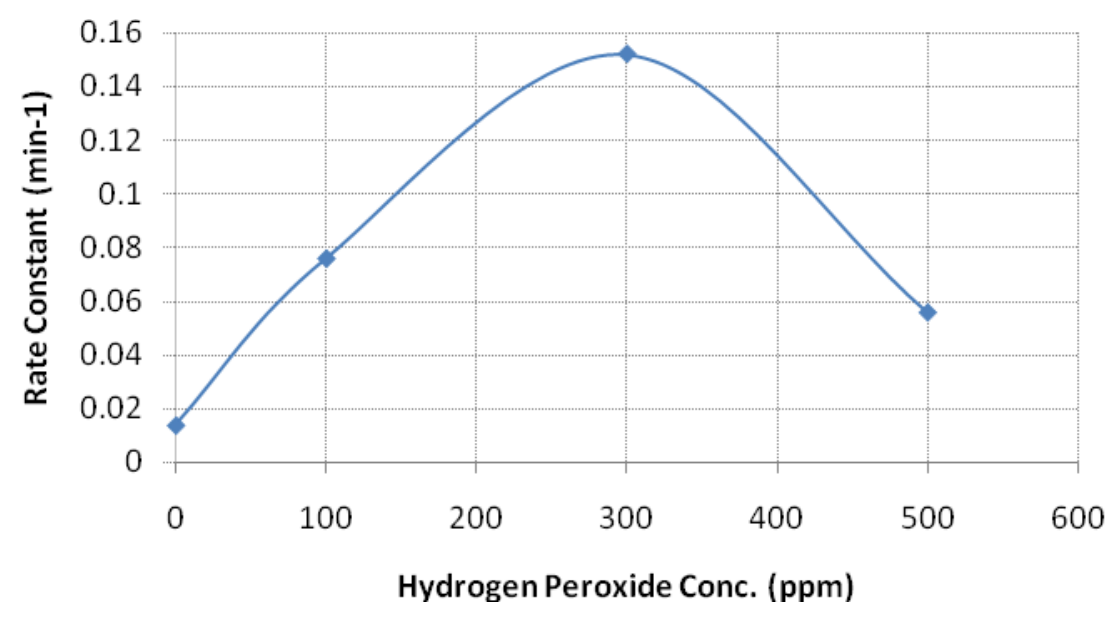

Fig. 6 Effect of $\mathrm{H}_{2} \mathrm{O}_{2}$ on the rate of photochemical degradation of pyridine at initial concentration of pyridine $\mathrm{C}_{0}=100 \mathrm{ppm}$ at $25^{\circ} \mathrm{C}$.

During this process, ultraviolet radiation is used to cleave the $\mathrm{O}-\mathrm{O}$ bond in hydrogen peroxide and generate the hydroxyl radical. The reactions describing $\mathrm{UV} / \mathrm{H}_{2} \mathrm{O}_{2}$ process are presented below [28].

$$
\begin{aligned}
& \mathrm{H}_{2} \mathrm{O}_{2}+\mathrm{uv} \rightarrow 2 \mathrm{HO} \\
& \mathrm{H}_{2} \mathrm{O}_{2}+\mathrm{HO} \bullet \rightarrow \mathrm{HO}_{2} \bullet+\mathrm{H}_{2} \mathrm{O} \\
& \mathrm{H}_{2} \mathrm{O}_{2}+\mathrm{HO}_{2} \bullet \rightarrow \mathrm{HO} \bullet+\mathrm{H}_{2} \mathrm{O}+\mathrm{O}_{2} \\
& 2 \mathrm{HO} \bullet \rightarrow \mathrm{H}_{2} \mathrm{O}_{2} \\
& 2 \mathrm{HO}_{2} \bullet \rightarrow \mathrm{H}_{2} \mathrm{O}_{2}+\mathrm{O}_{2} \\
& \mathrm{HO} \bullet+\mathrm{HO}_{2} \bullet \rightarrow \mathrm{H}_{2} \mathrm{O}+\mathrm{O}_{2}
\end{aligned}
$$

In the previous equations, Eq. 16 is the rate limiting reaction because the rates of the other reactions are much higher than that of Eq. 16. Theoretically in $\mathrm{UV} / \mathrm{H}_{2} \mathrm{O}_{2}$ process, the higher initial hydrogen peroxide concentration produces higher hydroxyl radical concentration, which cause more degradation of pyridine. However, an optimal hydrogen peroxide concentration exists because overdosing of hydrogen peroxide would lead to reaction with 
hydroxyl radical and formation of $\mathrm{HO}_{2}$ (Eq. 17). Moreover, there is an optimum concentration for $\mathrm{H}_{2} \mathrm{O}_{2}$. Beyond this limit, the presence of $\mathrm{H}_{2} \mathrm{O}_{2}$ is detrimental to the degradation reaction due to scavenging action. Therefore, the combination of UV with $\mathrm{H}_{2} \mathrm{O}_{2}$ was necessary for the production of hydroxyl radicals to initiate the degradation of pyridine at a reasonable time scale even for the higher pyridine concentrations. These results are in good agreement with other findings in literature, such as Aleboyeh et al. [29] who showed that a combination of UV plus $\mathrm{H}_{2} \mathrm{O}_{2}$ in comparison with UV alone increases removal rates of Acid Orange 8 and Methyl Orange, 172 and 137 times, respectively. In this view, the UV radiation is combined with a powerful oxidant, $\mathrm{H}_{2} \mathrm{O}_{2}$; the degradation efficiency of pyridine is significantly enhanced due to hydroxyl radical production caused by the photolysis of $\mathrm{H}_{2} \mathrm{O}_{2}$, as reported by other researchers [30].

In conclusion, results with $\mathrm{UV} / \mathrm{H}_{2} \mathrm{O}_{2}$ and $\mathrm{US} / \mathrm{H}_{2} \mathrm{O}_{2}$ processes indicate that the oxidation was exclusively due to hydroxyl radical attack when hydrogen peroxide was in excess. Pyridine degradation rate by US and US/ $\mathrm{H}_{2} \mathrm{O}_{2}$ was strongly dependent on initial concentration of hydrogen peroxide, as shown in Figure 4 . Figure 5 shows $\mathrm{UV} / \mathrm{H}_{2} \mathrm{O}_{2}$ is more efficient than UV light alone for Pyridine degradation. Comparison of photo-degradation and sono-degradation rate constant Table 2 showed that photo degradation of Pyridine was more efficient than sonodegradation. The results indicated that in the $\mathrm{UV} / \mathrm{H}_{2} \mathrm{O}_{2}$ and $\mathrm{US} / \mathrm{H}_{2} \mathrm{O}_{2}$ systems, a sufficient amount of $\mathrm{H}_{2} \mathrm{O}_{2}$ was necessary, but a very high $\mathrm{H}_{2} \mathrm{O}_{2}$ concentration would inhibit the reaction rate. The optimum $\mathrm{H}_{2} \mathrm{O}_{2}$ concentration was achieved in the range of $100-300 \mathrm{ppm}$ at pyridine concentration of $100 \mathrm{mg} / \mathrm{L}$. A degradation of $99 \%$ was obtained with $\mathrm{UV} / \mathrm{H}_{2} \mathrm{O}_{2}$ within 5 minutes while degradation efficiency by using UV $(<20 \%)$, US $(<2 \%)$ and $\mathrm{US} / \mathrm{H}_{2} \mathrm{O}_{2}(<10 \%)$ processes were negligible for this kind of pollutant at these specified operating conditions.

Table 2. The apparent first order rate constants and half-life time for the sonochemical and photolytic degradation processes at various conditions of pyridine solution with initial concentration of $100 \mathrm{ppm}$.

\begin{tabular}{lccc}
\hline \multicolumn{1}{c}{ Type of process } & $\begin{array}{c}\text { Rate constant } \\
K\left(\mathrm{~min}^{-1}\right)\end{array}$ & $\mathrm{T}_{1 / 2}(\min )$ & $\mathrm{R}^{2}$ \\
\hline $\mathrm{US}$ & 0.002 & $>200$ & 0.97 \\
$\mathrm{US} / \mathrm{H}_{2} \mathrm{O}_{2}(100 \mathrm{ppm})$ & 0.004 & $>120$ & 0.99 \\
$\mathrm{US} / \mathrm{H}_{2} \mathrm{O}_{2}(300 \mathrm{ppm})$ & 0.005 & $>90$ & 0.97 \\
$\mathrm{US} / \mathrm{H}_{2} \mathrm{O}_{2}(500 \mathrm{ppm})$ & 0.006 & $>60$ & 0.95 \\
$\mathrm{UV}$ & 0.014 & 50 & 0.98 \\
$\mathrm{UV} / \mathrm{H}_{2} \mathrm{O}_{2}(100 \mathrm{ppm})$ & 0.076 & $<10$ & 0.99 \\
$\mathrm{UV} / \mathrm{H}_{2} \mathrm{O}_{2}(300 \mathrm{ppm})$ & 0.152 & $<5$ & 0.99 \\
$\mathrm{UV} / \mathrm{H}_{2} \mathrm{O}_{2}(500 \mathrm{ppm})$ & 0.056 & 10 & 0.99 \\
\hline
\end{tabular}

\section{Conclusion}

In this experimental study, degradation of pyridine was investigated by using several advanced oxidation processes: US, US plus $\mathrm{H}_{2} \mathrm{O}_{2}$, UV and UV plus $\mathrm{H}_{2} \mathrm{O}_{2}$. Optimal operating conditions for each process were established. The conclusions drawn from this study can be summarized as follows: The degradation efficiency proceeded very slowly when US, US plus $\mathrm{H}_{2} \mathrm{O}_{2}$ and UV processes were used. UV plus $\mathrm{H}_{2} \mathrm{O}_{2}$ process was found to be a suitable treatment method for complete degradation for pyridine within very short time. The reaction rate constant was increased with increasing $\mathrm{H}_{2} \mathrm{O}_{2}$ concentration; however, the marginal benefit became decreasing with further increasing of $\mathrm{H}_{2} \mathrm{O}_{2}$ due to the scavenging effect of excess $\mathrm{H}_{2} \mathrm{O}_{2}$. Pseudo-first order kinetics with respect to pyridine concentrations was found to fit all the experimental data. 


\section{References}

1. P. Kln, and M. Vavrik, Non-catalytic remediation of aqueous solutions by microwaveassisted photolysis in the presence of $\mathrm{H}_{2} \mathrm{O}_{2}$, J. Photochem. Photobiol. A 177 (2006) 2433.

2. Gogate P.R. and Pandit A.B. A review of imperative technologies for wastewater treatment I: oxidation technologies at ambient conditions, Adv. Environ. Res., 8, (2004) 501-551.

3. SES The UV/Oxidation Handbook, Solarchem Environmental Systems, Markham, Ontario, Canada (1994).

4. Y. Shiying, W. Ping, Y. Xin, W. Guang, Z. Wenyi, and S. Liang, A novel advanced oxidation method to degrade organic pollutants in wastewater: microwave activated persulfate oxidation, J. Environ. Sci. 21 (2009) 1175-1180.

5. T.L. Lai, C.C. Lee, G.L. Huang, Y.Y. Shu, and C.B. Wang, Microwave-enhanced catalytic degradation of 4-chlorophenol over nickel oxides, Appl. Catal. B: Environ. 78 (2008) 151-157.

6. A. Vogelpohl, SM Kim; Advanced oxidation processes (AOPs) in wastewater treatment. J. Ind. Eng. Chem., 10 (2004), pp 33-40.

7. P.R. Gogate, and A.B. Pandit; A review of imperative technologies for wastewater treatment I: oxidation technologies at ambient conditions; Adv. Environ. Res. 8 (2004) 501-551.

8. P.R. Gogate, and A.B. Pandit, A review of imperative technologies for wastewater treatment II: hybrid methods; Adv. Environ. Res. 8 (2004) 553-597.

9. S. Zhu, P.R.F. Bell, and P.F. Greenfield, Adsorption of pyridine onto spent rundle oil shale in dilute aqueous solution, Water Res. 22 (10) (1988) 1331-1337.

10. H. Paige and OYAMA S. Ted, Control of volatile organic compound emissions, conventional and emerging technologies. (2000).

11. A. K. Mathur, C.B. Majumderb,, S. Chatterjee, and P. Roy. Biodegradation of pyridine by the new bacterial isolates S. putrefaciens and B. sphaericus Journal of Hazardous Materials 157 (2008) 335-343.

12. K.V. Padoley, A.S. Rajvaidya, T.V. Subbarao, and R.A. Pandey Biodegradation of pyridine in a completely mixed activated sludge process. Bioresource Technology 97 (2006) 1225-1236.

13. De Visscher, A., Van Eenoo, P., Drijvers, D., and Langenhove, H.V., Kinetic model for the sonochemical degradation of monocyclic aromatic compounds in aqueous solution., $\mathrm{J}$. Phys. Chem.1996; 100: 11636-11642.

14. De Visscher, A., Van Eenoo, P., Drijvers, D., and Langenhove, H.V., Kinetic model for the sonochemical degradation of monocyclic aromatic compounds in aqueous solution., J. Phys. Chem.1996; 100: 11636-11642.

15. Jiang, Y., Petrier, C. and Waite, T.D., Kinetics and mechanisms of ultrasonic degradation of volatile chlorinated aromatics in aqueous solutions., Ultrasonics Sonochemistry. 2002; 9: 317-323.

16. C. G. da Silva, J. Lu'is Faria. Photochemical and photocatalytic degradation of an azo dye in aqueous solution by UV irradiation. Journal of Photochemistry and Photobiology A: Chemistry 155 (2003) 133-143.

17. R David. A Stapleton, B. D. Mantzavinos, and C. M. Papadaki,. Photolytic (UVC) and photocatalyic (UVC/TiO2) decomposition of pyridines. Journal of Hazardous Materials 146 (2007) 640-645.

18. K. Vinodgopal, O. Makogon and P.V. Kamat, Ultrasonic mineralization of a reactive textile azo dye, remazol black B, Water Res., 32, 3646 (1998). 
19. Feifang Zhang, Ayfer Yediler , Xinmiao Lianga, Antonius Kettrup, Effects of dye additives on the ozonation process and oxidation by-products: a comparative study using hydrolyzed C.I. Reactive Red 120, 60, 1, ( 2004), 1-7.

20. Thiruvenkatachari R, Vigneswaran S, Moon I A review on UV/TiO2 photocatalytic oxidation process (Journal Review). Korean J Chem Eng 25 (1): (2008), 64-72

21. E. Naffrechoux, S. Chanoux, C. Petrier and J. Suptil, Sonochemical and photochemical oxidation of organic matter, Ultrasonics Sonochem., 7, 255 (2000).

22. D. R. STAPLETON, R. J. EMERY, D. MANTZAVINOS and M. PAPADAKI. Photolytic destruction of halogenated pyridines in wastewaters. Process Safety and Environmental Protection, 84(B4), (2006) 313-316.

23. Y. L. Pang, A. Z. Abdullah, and S. Bhatia. Review on sonochemical methods in the presence of catalysts and chemical additives for treatment of organic pollutants in wastewater.

24. T.E. Agustina , H.M. Ang, and V.K. Vareek. A review of synergistic effect of photocatalysis and ozonation on wastewater treatment. Journal of Photochemistry and Photobiology C: Photochemistry Reviews 6 (2005) 264-273.

25. C. Gong and D. P. Hart. Ultrasound Induced Cavitation and Sonochemical Yields. Journal of the Acoustical Society of America, Vol. 104, 1998.

26. M. Abbasi, and N.R. Asl, Sonochemical degradation of Basic Blue 41 dye assisted by nanoTiO $\mathrm{TiO}_{2}$ and $\mathrm{H}_{2} \mathrm{O}_{2}$, J. Hazard. Mater. 153 (3) (2008) 942-947.

27. M. Goel, H. Hongqiang, A.S. Mujumdar, and M.B. Ray, Sonochemical decomposition of volatile and non-volatile organic compounds - a comparative study, Water Res. 38 (19) (2004) 4247-4261.

28. Buxton G.V., Greenstock W., Helman P. and Ross A.B. Critical review of rate constants for reactions of hydrated electrons, hydrogen atoms and hydroxyl radicals in aqueous solution, J. Phys. Chem. Ref. Data, 17, (1988) 513-886.

29. A. Aleboyeh, H. Aleboyeh and Y. Moussa, Dyes Pigm., 57, 67(2003).

30. F. J. Beltran, Ozone-UV radiation-hydrogen peroxide oxidation technologies. In: Tarr, M.A. (Ed.), Chemical Degradation Methods for Wastes and Pollutants. Environmental and Industrial Applications. Marcel Dekker, Inc., New York, USA (2003). 